\title{
An Overview of the Use of Placards and the Potential Benefits for British Columbians
}

\author{
Pardip Dhaliwal $^{1}$, Helen Heacock ${ }^{2}$ \\ 1 Lead Author, B. Tech Student, School of Health Sciences, British Columbia Institute of Technology, \\ 3700 Willingdon Ave, Burnaby, BC V5G 3H2 \\ 2 Supervisor, School of Health Sciences, British Columbia Institute of Technology, 3700 Willingdon \\ Ave, Burnaby, BC V5G 3H2
}

\begin{abstract}
$\underline{\text { Abstract }}$
Background: Environmental Health Officers (EHOs) are responsible for assessing the risk that food establishments pose to the public through regular inspections. The results of these inspections are then posted online for the public to view in British Columbia (BC). However, cities such as Toronto and New York City, have adopted the use of placards that are visibly placed at each food establishment, as well as posting the results online. The purpose of the placards is to provide a quick method for the public to ascertain the safety of food establishments. The use of placards has been shown to increase the compliance of food operators, as well as play a role in reducing foodborne illnesses. The purpose of this study was to determine if British Columbians would like to have the results of health inspections displayed on a placard in food establishments, in addition to them being posted online.
\end{abstract}

Methods: An online, self-administered survey was created on SurveyMonkey Canada and distributed to residents of $\mathrm{BC}$ through Facebook and Reddit. The survey took approximately five minutes to complete and responses were collected over a nine-day period. The data was then analyzed using NCSS software.

Results: From the 176 respondents, it was determined that approximately $44 \%$ of people knew about health inspection reports being posted online in $\mathrm{BC}$, however, only $33 \%$ of people have visited health authority websites to view the inspections. $93 \%$ of the respondents would like to see a placard system implemented in BC. Furthermore, $72 \%$ of respondents would like to see a letter grade ranking of placards as opposed to a more general "Pass", Conditional Pass" or "Closed" system. Results indicated a statistically significant association between the desire for a placard system and selecting a restaurant to eat at $(\mathrm{p}=0.000)$. Whether or not one views an online inspection report had no bearing on whether a placard system was desired. $(p=0.231)$. There is no association between age of $\mathrm{BC}$ residents and the preference for placards in $\mathrm{BC}(\mathrm{p}=0.618)$. However, there was an association between the age of respondents and knowledge of online reports of health inspections $(\mathrm{p}=0.008)$, indicating that younger people are less likely to know about online health inspections that older populations.

Conclusion: The results of this research study indicated that residents of BC overwhelmingly support the use of placards. BC residents would also like to see a letter grade placard system implemented. Although BC residents would like to see placards in food establishments, further research is required to assess what food operators, as well as other EHOs, think about implementing a placard system in place in food establishments. 
Keywords: Environmental Health Officers, placards, British Columbia, food establishments, food operators, inspection

\section{Introduction}

British Columbia (BC) has a thriving restaurant industry, with sales totalling over $\$ 1$ billion in 2018 alone ("Industry Overview: Restaurants | Small Business Accelerator," 2019). However, an inherent problem with the restaurant industry is that food can be dangerous if proper food safety and food handling techniques are not followed. The consequence of improper food safety and handling are foodborne illnesses (FBIs). Specifically, the British Columbia Centres for Disease Control (BCCDC) estimates that there are approximately 550,000 cases of foodborne illnesses every year (Hand Contact with Food: A Major Cause of Foodborne Illness, 2014.). In order to limit the number of foodborne illnesses in BC, Environmental Health Officers (EHOs) inspect food establishments to determine if safe food handling, proper temperature control of foods, and appropriate sanitation levels are being met according to the legislation ("Food facilities inspection reports and violation tickets," n.d.). The purpose of restaurant inspection reports is to let the operators know where they may have deficiencies in their establishments and the corrective measures that must be completed. At the end of the inspection, the EHOs assign a hazard rating of 'Low', 'Medium', or 'High', to each establishment, with each hazard rating increasing in terms of risks to the public at that location ("Northern Health Public Health Protection," n.d.). The results of these inspections are then posted online, accessible to the public so that they may make informed decisions on where they dine. However, posting these results online does not prevent outbreaks of FBIs, as inspections at establishments are periodic and do not have a significant impact on the day-to day food safety practices (Megan Griffith-Greene / Marketplace · CBC News, 2014). Since posting inspection reports online is not necessarily effective at increasing compliance from operators, or decreasing the number of FBIs, a new method to improve operator compliance, such as using placards, could be considered.

Placed in visible locations in restaurants, placards deliver the message of inspection reports in a quick, visual method. Instead of going online to look at inspection reports to determine the safety of the restaurant, the public can view the placard, displaying the result of the inspection, and make an informed opinion. This paper examines whether British Columbians would like to see a placard system implemented in BC.

\section{$\underline{\text { Literature Review }}$}

Placards may come in different forms. For example, the city of Toronto implemented DineSafe, a program that conducts inspections on food premises and assigns hazard rankings to each premise, accordingly, as seen in Figure 1. After an inspection, a placard is assigned to each 


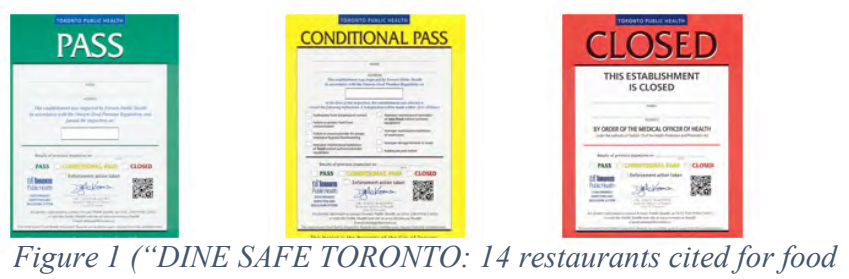
violations this week | Toronto.com," 2019)

food establishment, depending on the result of the inspection. The placard assigned can both be viewed physically at the food establishment, or online on the DineSafe website. The website not only shows the placard assigned to each individual food establishment, but also provides further information regarding the inspection, such as any infractions. DineSafe utilizes three different notices: 'Pass', 'Conditional Pass', and 'Closed'. A 'Pass' notice indicates that there was either no infraction, or only minor infractions. 'Conditional Pass' is used when there are one or more significant infractions, and the restaurant will be re-inspected within 24-48 hours. If these infractions are corrected, then a 'Pass' notice is given, otherwise progressive enforcement will take place, involving another inspection, tickets and a summons to court. A 'Closed' notice is when a restaurant has failed inspection due to an urgent health hazard and must be corrected immediately. Once corrected, another inspection will take place and a 'Pass' notice will be given if there are no more problems at the restaurant ("DineSafe Inspection and Disclosure System-Toronto Public Health," 2012.).

Another common type of placard system utilizes a letter grade system, which is seen in cities such as Los Angles and New York City. In New York City (NYC), points are awarded for infractions during inspections, with more points for the more serious infractions. Restaurants that have a final score of 0 to 13 points are given an ' $A$ ', 14 to 27 points are given a ' $\mathrm{B}$ ', and finally, $28+$ points are awarded a 'C' ("NYC Restaurant Health Inspections-ABC Grading System," n.d.). The better the letter grade, the lower the points awarded during inspection, and ultimately, less infractions observed during inspection.

Although there may be different systems when it comes to placards, the overall goal is the same. Placards can be used as a tool for conveying how risky a food establishment may be, as well as a tool for compliance amongst operators (Seiver \& Hatfield, 2002).

To prevent FBIs, food establishments have certain rules to follow. However, these rules are not followed fully by all operators, which is why enforcement from EHOs is extremely important. EHOs ensure that there is compliance of the legislation regarding food safety to ensure the safety of the public. A significant method to increase compliance amongst operators would be the utilization of placards. In New York, the use of placards and the letter grade system began in 2010 . By examining data from 2011, McKelvey, Wong, and Matis noticed there was a significant rise in compliance. In 2011, only $72 \%$ restaurants in NYC had an 'A' grade. By 2014, the number of restaurants having 'A' grades moved up to $85 \%$ (Mckelvey, Wong, \& Matis, 2015). A visual representation of the compliance in NYC 
can be seen in Figure 2. The red highlights where the percentage of restaurants receiving an ' $A$ ' grade is $61.9 \%$. As the color fades from a deep red to a faded yellow, the percentage picks up to a range of $81.4 \%-92.9 \%$. From the figure, it can be observed that the percentage of restaurants

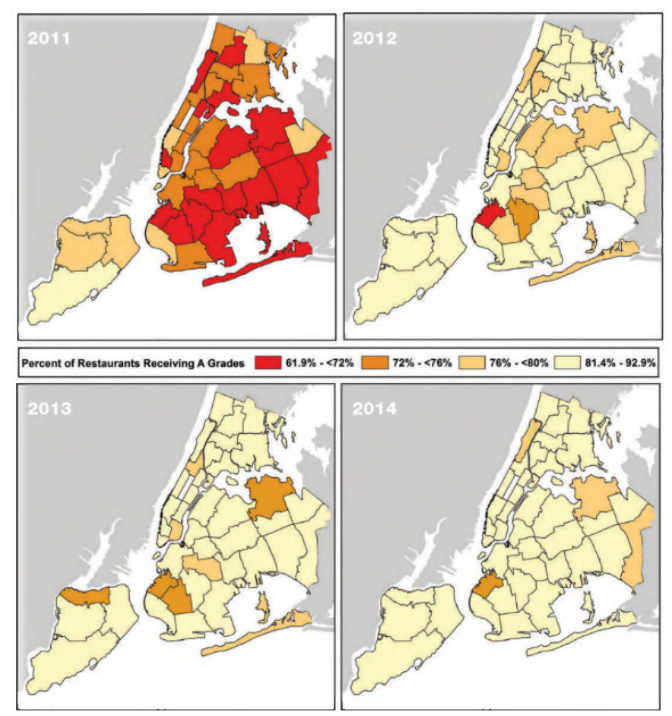

Figure 2 (Mckelvey, Wong, \& Matis, 2015) receiving ' $A$ ' grades significantly increased. Wong et al. further researched into the impact of adding the letter grade system in NYC before and after the program was implemented. Wong et al. utilized data from July 2007 to July 2013, collecting three years of data before and three years of data after the letter grade system was implemented. In total, data from 43, 448 restaurants were gathered to measure the inspection scores. After running a binomial regression test, Wong et al. determined that the probability of receiving an ' $A$ ' grade (between 0 to 13 points) increased by $35 \%$ (95\% confidence interval $[\mathrm{CI}]=31 \%, 40 \%$, indicating a significant finding) three years after the letter grade system was implemented (2013) compared to before the program began (2007). An important reason why there was an overall increase in the restaurants receiving an ' $\mathrm{A}$ ' was due to compliance of having a certified kitchen manager at food establishments, which lead to fewer critical violations. Another important factor was compliance with proper handwashing and worker hygiene (Wong et al., 2015). Overall, the use of a letter grade placard in NYC has been observed to increase compliance in food operators.

Although the use of placards can be viewed as beneficial for compliance, there are some significant issues that have arisen. To determine the effectiveness of the letter grade system, Ho looked at data from San Diego and noticed a significant problem. Observing 11,813 restaurants in San Diego, Ho plotted out the number of restaurants receiving an 'A' grade on a histogram which can be seen in Figure 3. Each black bar coincides with the frequency of restaurants receiving that score. The black line at 90 represents the threshold for receiving and ' $A$ ' grade. As observed in the Figure 3, most restaurants obtain an ' $A$ ' grade. 703

restaurants scored 90 on the inspection while INSPECTION SCORES IN SAN DIEGO

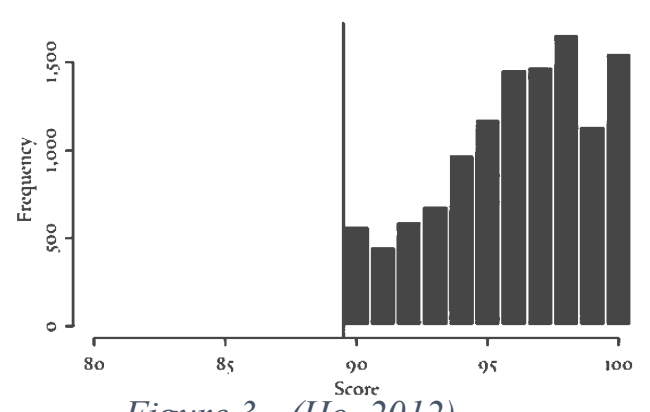

Figure 3 - (Ho, 2012)

only two scored 89 , just below the threshold for an 'A' grade. Ho does state that this may be due to improvements in cleanliness, however, there are reasons to suggest that 
this is not the case. Restaurants can pay a fee in order to be re-inspected and regraded. Ho notes that approximately $25 \%$ of restaurants receive an 'A' grade on initial inspection, and that moves up to $80 \%$ within a month. Therefore, the letter grade placard system can be taken advantage of. Higher levels of compliance may only be temporary, until reinspection. If almost all restaurants receive an ' $A$ ' grade or the chance to get an ' $A$ ' by essentially paying a fee, the letter grade system cannot be an effective tool for compliance. NYC has somewhat of a different problem. Restaurants that are not given an ' $A$ ' upon initial inspection can still be given an ' $A$ ' based on re-inspection, which normally occurs within a month. If the restaurant still does not obtain an ' $\mathrm{A}$ ' during re-inspection, they can either accept the grade given, or take the 'Grade Pending' sign while the operator disputes the grade to an administrative tribunal (Ho, 2012). San Diego and NYC present important issues that need to be addressed before considering implementing a placard program in $\mathrm{BC}$. Restaurants should be given a chance for reinspection if they do not receive an ' $\mathrm{A}$ ' grade on initial inspection. However, the goal should not be to give all restaurants an ' $A$ ' as that renders the significance of the grade meaningless. Also, grades should be final after re-inspection, until the next random inspection occurs. There should be no 'Grade Pending' notice.

An important factor to consider for compliance of restaurants in respect to placards is the public perception of the placards. If the public has no opinion, or does not place any value on the placards, they cannot be seen to be effective tools.
After the implementation of DineSafe in 2001, Toronto Public Health conducted a survey regarding DineSafe and the disclosure program. The purpose of the survey was to determine the awareness, knowledge, impact, as well as attitude towards DineSafe. The results of the survey showed that approximately $75 \%$ of the public was mostly aware of the notices posted in the restaurants, only $21 \%$ were aware of the inspections that EHOs conducted and only $10 \%$ were aware of the DineSafe website which posted the results of the inspection online. In addition, the survey also determined which method the public would most likely use when it came to the disclosure of the results of the inspection. $85.9 \%$ of the people surveyed would use the notices, while only $20.8 \%$ would use the DineSafe website. Furthermore, 95.5\% of the people who use the notices would go to food establishments that have a 'Pass' notice on it as opposed to one with a 'Conditional' (21.8\%) or 'Closed' (16.8\%). Most importantly, $84.1 \%$ of people surveyed felt an increase of safety after the use of the placards, and $97.4 \%$ of people felt that the use of placards was important and supported it. Wong et al. also conducted a survey on the public perception of the placard systems in NYC. One survey was conducted one year after implementing the letter grade system, with the second survey taking place at 18 months. Results from the survey showed strong support of the program, with $90 \%$ of people approving of the program in the first year and 91\% supporting the program after 18 months. $76 \%$ of people felt more confident when a restaurant had an 'A' grade (Wong et al., 2015). The results of 
these surveys clearly show how important the public perceive the placards to be (Food Premises Inspection and Disclosure System, 2002). With an overwhelming support among the public in Toronto and NYC for the placards, it can be assumed that the majority of the population prefers a quick and effective method to view the results of an inspection and that this method could be desired in BC.

The use of placards can also have an impact on the spread of disease specifically FBIs. Firestone and Hedberg inspected the rates of Salmonella infection before and after the use of letter grades in NYC, from the years 1994 to 2015. Data was also collected from New York State (NYS) to use as a comparison, as the state does not use the letter grade system. From observing the data, Firestone and Hedberg noticed that there was a downward trend in the rates of Salmonella infections in both NYC and NYS. However, NYC had a much more significant decrease, a total of $32.6 \%$ compared to NYS, which had a reduction of $14.1 \%$. Before the implementation of the letter grade system, NYC had a higher mean Salmonella infection rate than NYS, but after the letter grade system, there was no significant difference between the two. It is important to note that this study does not represent a causal relationship, but rather an association. Also, during the time of implementation of the letter grades, NYC made some changes to their inspections, including the frequency of inspections, higher risks for fines, as well as more training opportunities. It is unknown which had the greatest impact on the reduction of Salmonella infections (Firestone \& Hedberg,
2018). Although a direct link cannot be established between the use of letter grades in NYC and the rate of Salmonella infections, it cannot be denied that the use of placards has an impact. Therefore, it can be said that placards may have a role in the decrease of FBIs within the food industry.

The use of placards can be extremely beneficial for a multiple of reasons. If proper steps are taken to ensure that the use of a placard system is not abused, placards can increase the compliance of food operators. Also, the use of placards is supported by the majority of the people in cities that already use the system, indicating that this is a system that the general public would like to see. Knowing that food is prepared in a safe and cleanly method makes people feel confident about their dining choices.

Furthermore, placards appear to have a role in the reduction of FBIs, allowing the public to make safer choices when dining. These are important factors that could have a major impact, if the use of placards is implemented in BC. The current inspection system could be utilized in tandem with the placard system, meaning that it would not need to be completely changed. With the use of a placard system, British Columbians can make informed decisions when dining out, choosing restaurants with a level of risk that they may feel comfortable with.

\section{Purpose of the Study}

The purpose of this research study was to determine if British Columbians would like to see the results of a health inspection on a placard system in food establishments, in addition to the results being posted online. The results of this 
research can help determine if policy change is required regarding inspection results.

\section{Materials and Methods}

$\underline{\text { Materials }}$

Over the course of this research study, the only material required was a computer. A survey was hosted on SurveyMonkey, an online survey tool (It's All About Powering the Curious, n.d.). The software to analyze the results of the survey used was NCSS 2019 (Statistical Software | Sample Size Software | NCSS, n.d.)

$\underline{\text { Standard Methods }}$

The survey was an online, selfadministered survey hosted by SurveyMonkey Canada from January 14, 2020 to January 23, 2020. The survey was posted online through the social media platforms Reddit and Facebook.

The survey consisted of three different sections based on the author's knowledge about food safety, inspections, and placards. First, there were questions to acquire data on the demographic factors. The second part of the survey asked questions regarding the knowledge and use of inspection reports from Health Authorities in BC. Lastly, the survey contained questions to determine the public's view on the use of placards in food establishments, displaying the results of health inspections.

$\underline{\text { Inclusion and Exclusion Criteria }}$

The research study examined the opinions of the general public in British Columbia. Participants were informed at the beginning of the survey that the survey is only for residents of British Columbia. Participants outside of British Columbia were excluded from the analysis.

Participants were also made aware that the survey was meant for people older than 12 years age. The survey was only distributed in English, thus excluding any non-English speakers.

\section{Statistical Analysis}

$\underline{\text { Descriptive Statistics }}$

Survey Monkey compiled and presented descriptive statistics, such as demographic data, as pie and bar charts.

The 21-30 age group made up most of the people surveyed, representing $44.89 \%$. The next largest age group of people surveyed was 31-40, representing $21.02 \%$. The $51+$ age group represented $13.64 \%$.

Of the 176 people surveyed, 55.11\% were women, while only $41.48 \%$ were men. $1.14 \%$ identified as other while $2.27 \%$ preferred not to answer.

A total of $44.57 \%$ of people knew about the inspection forms being posted online. $55.43 \%$ of people did not know.

$67.05 \%$ of people have never used a health authorities' website to view the reports on food establishments, whereas $32.95 \%$ have used the website. 
Q10 Placards are currently being used in Toronto, as well as some states in America, to display the results of the inspection report in a visible location within the restaurant (View image below)Would you prefer to see a system like this in $B C$ ?

Answered: 176 Skipped: 14

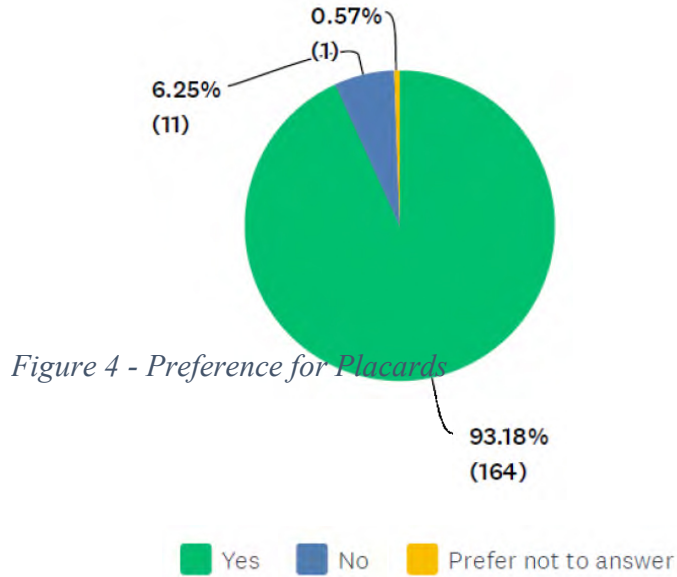

Overall, $93.18 \%$ of the people surveyed preferred a placard system in BC and $6.25 \%$ did not.

If a placard system was implemented, $72.16 \%$ of people would like to see a letter grade system, $26.14 \%$ of people would like to a Pass, Conditional Pass, or Closed system. $1.70 \%$ of people preferred not to answer.

Q7 Did you know you can view inspection reports for food establishments online in BC?

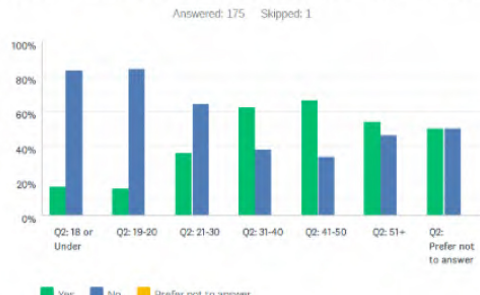

Figure 5 - Age and Knowledge of Inspection Reports People under the age of 30 generally were less aware of the inspection reports on food establishments being available online compared to people over 30 .

Inferential Statistics
Inferential statistics was used in this research study. As data was collected from the survey questionnaire, Chi Square tests were used to determine if there was a difference in proportions of outcomes between two or more groups (Heacock \& Chen, n.d.).

\section{Statistical Package Used}

SurveyMonkey Canada provided the descriptive statistics after the surveying period was completed.

Raw data was imported into NCSS 2019 to conduct Chi Square tests for inferential statistics. Results from NCSS 2019 provided insight if there was any statistical significance for the hypotheses being tested (Table 1).

Table 1. Hypotheses 


\begin{tabular}{|c|c|c|c|}
\hline $\mathrm{H}_{\mathrm{o}}$ and $\mathrm{H}_{\mathrm{a}}$ & Test Used & Result & Conclusion \\
\hline $\begin{array}{l}\text { 1) } \mathrm{H}_{0} \text { : There is no association between how many } \\
\text { times a person eats out per week and the preference } \\
\text { for placards in BC. } \\
\mathrm{H}_{\mathrm{a}} \text { : There is an association between how many } \\
\text { times a person eats out per week and the preference } \\
\text { for placards in BC. }\end{array}$ & Chi-Squared & $\mathrm{P}=0.982$ & $\begin{array}{l}\text { Do not reject null } \mathrm{H}_{0} \text { and conclude } \\
\text { there is no association between } \\
\text { how many times a person eats out } \\
\text { per week and the preference for } \\
\text { placards. }\end{array}$ \\
\hline $\begin{array}{l}\text { 2) } \mathrm{H}_{0} \text { : There is no association between using online } \\
\text { services that review food establishments (Yelp, } \\
\text { Google Reviews...) and the preference for placards } \\
\text { in BC. } \\
\mathrm{H}_{\mathrm{a}} \text { There is an association between using online } \\
\text { services that review food establishments (Yelp, } \\
\text { Google Reviews...) and the preference for placards } \\
\text { in BC. }\end{array}$ & Chi-Squared & $\mathrm{P}=0.688$ & $\begin{array}{l}\text { Do not reject null } \mathrm{H}_{0} \text { and conclude } \\
\text { there is no association between } \\
\text { using online services that review } \\
\text { food establishments (Yelp, Google } \\
\text { Reviews...) and the preference for } \\
\text { placards in BC. }\end{array}$ \\
\hline $\begin{array}{l}\text { 3) } \mathrm{H}_{0} \text { : There is no association between age of } \mathrm{BC} \\
\text { residents and the preference for placards in } \mathrm{BC} \text {. } \\
\mathrm{H}_{\mathrm{a}} \text { : There is an association between age of } \mathrm{BC} \\
\text { residents and the preference for placards in } \mathrm{BC} \text {. }\end{array}$ & Chi-Squared & $\mathrm{P}=0.618$ & $\begin{array}{l}\text { Do not reject } \mathrm{H}_{0} \text { and conclude there } \\
\text { is no association between age of } \\
\mathrm{BC} \text { residents and the preference for } \\
\text { placards in } \mathrm{BC} \text {. }\end{array}$ \\
\hline $\begin{array}{l}\text { 4) } \mathrm{H}_{0} \text { : There is no association between viewing the } \\
\text { online inspection reports and the preference for } \\
\text { placards in BC. } \\
\mathrm{H}_{\mathrm{a}} \text { : There is an association between viewing the } \\
\text { online inspection reports and the preference for } \\
\text { placards in BC. }\end{array}$ & Chi-Squared & $\mathrm{P}=0.231$ & $\begin{array}{l}\text { Do not reject } \mathrm{H}_{0} \text { and conclude there } \\
\text { is no association between viewing } \\
\text { the online inspection reports and } \\
\text { the preference for placards in } \mathrm{BC} \text {. }\end{array}$ \\
\hline $\begin{array}{l}\text { 5) } \mathrm{H}_{0} \text { : There is no association between preferring a } \\
\text { placard system in } \mathrm{BC} \text { and referring to it when } \\
\text { looking or a place to eat. } \\
\mathrm{H}_{\mathrm{a}} \text { : There is an association between preferring a } \\
\text { placard system in } \mathrm{BC} \text { and referring to it when } \\
\text { looking or a place to eat. }\end{array}$ & Chi-Squared & $\mathrm{P}=0.000$ & $\begin{array}{l}\text { Reject } \mathrm{H}_{0} \text { and conclude there is an } \\
\text { association between preferring a } \\
\text { placard system in } \mathrm{BC} \text { and referring } \\
\text { to it when looking or a place to eat. } \\
\text { Those who prefer a placard system } \\
\text { are more likely to refer to it when } \\
\text { looking for a place to eat than those } \\
\text { who do not prefer placard systems. }\end{array}$ \\
\hline $\begin{array}{l}\text { 6) } \mathrm{H}_{0} \text { : There is no association between age and } \\
\text { knowing about online reports of health inspections. } \\
\mathrm{H}_{\mathrm{a}} \text { : There is an association between age and } \\
\text { knowing about online reports of health inspections. }\end{array}$ & Chi-Squared & $\mathrm{P}=0.008$ & $\begin{array}{l}\text { Reject } \mathrm{H}_{0} \text { and conclude there is an } \\
\text { association between age and } \\
\text { knowing about online reports of } \\
\text { health inspections. Younger } \\
\text { populations are less likely to know } \\
\text { about online health inspection } \\
\text { reports than older populations }\end{array}$ \\
\hline
\end{tabular}

\section{Discussion}

The results of the survey showed that there is overwhelming support for the placard system to be put into place in BC. Consisting of diverse age groups, approximately $93 \%$ of the people surveyed were in favor of the placards. This result was to be expected, as previous studies conducted in both Toronto, which had an approval rating of 97.4\% (Food Premises Inspection and Disclosure System, 2002), and New York City, which had an approval rating of $90 \%$ after one year of a placard 
system (Wong et al., 2015), showed that the general public would prefer to see placards in food establishments.

The results of the survey also presented a stark contrast with certain previous studies. In Toronto, $21.8 \%$ of the people surveyed would go to a food establishment with a "Conditional" placard (Food Premises Inspection and Disclosure System, 2002), whereas in this research study, $81.25 \%$ of people surveyed claimed they would have no problem going into a food establishment with the equivalent placard. This may have to do with people becoming knowledgeable about fool quality and food safety. This knowledge may come from the $63.07 \%$ of people who made use of online review websites such as Yelp, Google Reviews, TripAdvisor, etc., or by the $44.57 \%$ of people who viewed the online inspection reports posted by health authorities.

The survey also contained an openended question asking respondents whether or not they liked the placard system and to explain why. The majority of the responses were supportive of the placard system. The support for placards was due to a few common themes. Many people believed the health authority websites that currently post the inspection reports online are difficult and inconvenient to navigate through. Some of the respondents did not know that inspection reports are published online and felt that it would be more transparent to have placards at the food establishment. In this research study, it was discovered that the majority of respondents under 30 years old did not know about inspection reports being posted online, as seen in Figure 15 and confirmed by Hypothesis 6. Many respondents also believed that by having a placard system, food operators would be held accountable and they would make more of an effort to have cleaner and safer establishments. In contrast, respondents who were against the use of placards believed that having placards would not necessarily improve food safety, and that small, independent establishments would be negatively impacted economically if they receive less then perfect.

The results of this research study can be considered both internally and externally valid. The questions in the survey were straightforward and simple to answer, especially after making some minor changes from the pilot study, making the results internally valid. However, question 9 from the survey can be seen as a leading question. It asks the respondent "Would you prefer to see a system [the use of placards] like this in BC". Instead, the question should be revised to "Would you like to see a placard system" to make the question less leading. The data was also externally valid due to the large $\mathrm{N}$ (176), the broad distribution of age groups, and the fairly even distribution of genders.

\section{$\underline{\text { Limitations }}$}

A major limitation in this study was the lack of time. Due to having a short collection period, there was a lack of exposure of the survey to the general public, which ultimately resulted in a lack of respondents. Although there was a total of 176 respondents, the research study would have benefited from more people simply by having more data. Furthermore, another limitation in this research study was that the 
survey was only available online. This restricted the respondents to be only those who use the internet and specifically visit websites such as Reddit and Facebook, as those sites are where the survey was posted. To improve upon this, the survey should also be conducted using various methods, such as disseminating the survey in person, as well as conducting surveys over the telephone. Sharing specifically to family and friends minimizes the externally generalizability because respondents are not randomly selected. Another limitation in this research study was that the survey questions were only available in English. BC is a highly diverse population, with many different cultures and languages. By restricting the survey to an English-speaking population, a large percentage of the population was missed. By having the survey translated, no minority group BC would be overlooked when collecting data. By improving upon these limitations, the resulting consequence would be an increase in the sample size, and subsequently improving the internal and external validity of the study.

\section{Knowledge Translation}

The results from this research study could be used to make policy or legislation regarding placards in food establishments. From the survey, it was determined that the people of BC would like to see a placard system implemented. Also, from this survey, it was determined that people would prefer a letter grade system as opposed to using a 'Pass, Conditional Pass, Closed' system. With this knowledge, a policy or legislation could be put into place with this consideration. Implementing a provincial wide placard system from scratch would be a monumental task. It would involve the all the health authorities in $\mathrm{BC}$ to have a standardized health inspection form, a rating system, and some training so that every EHO is consistent amongst each other when inspecting a food establishment. Although this would require some training and considerable administrative work, BC could refer to the DineSafe program to emulate and expand on that.

\section{Future Research}

Future student research ideas:

- Survey on the perception on placards from food establishment owners/managers

- Survey on the perception on placards from EHOs

- Survey on how to best standardize food establishment inspections and inspection reports

\section{Conclusion}

Placards are designed to provide a quick visual interpretation of a health inspection conducted by EHOs. From this research study, it was determined that the public in $\mathrm{BC}$ overwhelmingly supported a placard system to provide this information for food establishments. Specifically, residents of BC would prefer to have a letter grade placard system, as used in New York City, as opposed to a 'Pass, Conditional Pass, Closed' system used in Toronto. The results of this research could lead to changes regarding health inspections at food establishments at a policy or legislation level, province wide. Ultimately, this would 
have far reaching impacts, and significantly change the food industry in BC.

\section{Competing Interests}

\section{References}

1. DineSafe Inspection and Disclosure System-Toronto Public Health. (2012). Retrieved October 13, 2019, from https://www.toronto.ca/health/dinesafe/s ystem.htm

2. DINE SAFE TORONTO: 14 restaurants cited for food violations this week | Toronto.com. (2019, August 21). Retrieved November 17, 2019, from Toronto.com website: https://www.toronto.com/whatsonstory/9560176-dine-safe-toronto-14restaurants-cited-for-food-violations$\underline{\text { this-week/ }}$

3. Firestone, M. J., \& Hedberg, C. W. (2018). Restaurant Inspection Letter Grades and Salmonella Infections, New York, New York, USA. Emerging Infectious Diseases, 24(12), 2164-2168. https://doi.org/10.3201/eid2412.180544

4. Food facilities inspection reports and violation tickets. (n.d.). Retrieved October 13, 2019, from https://www.fraserhealth.ca/healthtopics-a-to-z/food-safety/food-facilitiesinspection-reports-and-violation-tickets

5. Food Premises Inspection and Disclosure System. (2002, December 17). Retrieved from https://www.toronto.ca/health/dinesafe/p df/food safety evaluation.pdf Food_safety_evaluation.pdf. (n.d.).

6. Hand Contact with Food: A Major Cause of Foodborne Illness. (2014, November).
The authors declare that they have no competing interests.

Retrieved October 13, 2019, from http://www.bccdc.ca/resourcegallery/Documents/HandContactNov14. pdf

7. Heacock, H., \& Chen, D. (n.d.-a). 2. Module 2- Research Design and Data Collection-ENVH-8400-0 - Research Methods-32130-Lecture. Retrieved November 18, 2019, from https://learn.bcit.ca/d21/le/content/56988 4/viewContent/3908550/View

8. Heacock, H., \& Chen, D. (n.d.-b). 4. Module 4- Introduction to Inferential Statistics-ENVH-8400-0 - Research Methods-32130-Lecture. Retrieved November 18, 2019, from https://learn.bcit.ca/d21/le/content/56988 4/viewContent/4069828/View

9. Helen Heacock, \& Chen, D. (n.d.). 6. Module 4B- Chi-Square-ENVH-84000-Research Methods-32130 Lecture. Retrieved November 18, 2019, from https://learn.bcit.ca/d21/le/content/56988 4/viewContent/3947395/View

10. Ho, D. E. (2012). Fudging the Nudge: Information Disclosure and Restaurant Grading. 122(3), 522-851.

11. Industry Overview: Restaurants | Small Business Accelerator. (2019, March 9). Retrieved October 13, 2019, from The University of British Columbia website: 
https://sba.ubc.ca/blog/industry-

overview-restaurants-2018

12. Mckelvey, W., Wong, M., \& Matis, B. (2015). Letter Grading and Transparency Promote Restaurant Food Safety in New York ... Journal of Environmental Health, 78(2), 46-49.

13. Megan Griffith-Greene / Marketplace · CBC News · Posted: (last). (2014, April 10). Restaurant inspections: Why results can be hard to find $\mid$ CBC News. Retrieved October 13, 2019, from CBC website:

https://www.cbc.ca/news/health/restaura nt-inspections-why-results-can-be-hardto-find-1.2604077

14. Northern Health Public Health Protection. (n.d.). Retrieved October 13, 2019, from https://www.healthspace.ca/Clients/NH A/NHA Website.nsf/food-frameset
15. NYC Restaurant Health InspectionsABC Grading System. (n.d.). Retrieved October 17, 2019, from https://www.ehagroup.com/foodsafety/new-york-abc-restaurant-grading/

16. Seiver, O. H., \& Hatfield, T. H. (2002). Grading systems for retail food facilities: Preference reversals of environ...: EBSCOhost. Retrieved October 17, 2019, from http://web.b.ebscohost.com/ehost/pdfvie wer/pdfviewer?vid=1\&sid=dc08c4f8$689 \mathrm{c}-43 \mathrm{e} 3-8 \mathrm{e} 5 \mathrm{c}-$ e3c77b16ea70\%40sessionmgr102

17. Wong, M. R. 1, mwong2@health. nyc. gov, McKelvey, W., Kazuhiko Ito1, Schiff, C., Jacobson, J. B., \& Kass, D. (2015). Impact of a Letter-Grade Program on Restaurant Sanitary Conditions and Diner Behavior in New York City. American Journal of Public Health, 105(3), e81-e87. https://doi.org/10.2105/ 